\title{
Inhibitory Effect of Phellinus baumii Extract on CFA-Induced Inflammation in MH-S Cells through Nuclear Factor- $\kappa B$ and Mitogen-Activated Protein Kinase Signaling Pathways
}

\author{
H. M. Arif Ullah $\mathbb{D}^{1,2}$ Yuan Yee Lee $\mathbb{D}^{1},{ }^{1}$ Bong-Sik Yun $\mathbb{D}^{3},{ }^{3}$ Sung Dae Kim $\mathbb{D}^{\mathbb{D}},{ }^{1}$ \\ and Man Hee Rhee $\mathbb{D D}^{1}$ \\ ${ }^{1}$ Department of Veterinary Medicine, Cardiovascular Research Institute and College of Veterinary Medicine, \\ Kyungpook National University, Daegu 41566, Republic of Korea \\ ${ }^{2}$ Department of Neurobiology, University of Utah, Salt Lake, UT, USA \\ ${ }^{3}$ Division of Biotechnology and Advanced Institute of Environment and Bioscience, \\ College of Environmental and Bioresource Sciences, Jeonbuk National University, Gobong-ro 79, Iksan 54596, Republic of Korea
}

Correspondence should be addressed to Man Hee Rhee; rheemh@knu.ac.kr

Received 23 June 2021; Revised 1 October 2021; Accepted 11 October 2021; Published 25 October 2021

Academic Editor: Saeideh Saadat

Copyright (c) 2021 H. M. Arif Ullah et al. This is an open access article distributed under the Creative Commons Attribution License, which permits unrestricted use, distribution, and reproduction in any medium, provided the original work is properly cited.

\begin{abstract}
Phellinus baumii is a mushroom utilized as a traditional medicine for a wide range of human ailments, including diabetes, hypertension, hypercholesterolemia, and cancer, in Asia. The purpose of this study was to find out whether Phellinus baumii extract (PBE) could reduce inflammation caused by coal fly ash (CFA) in alveolar macrophages (MH-S). The anti-inflammatory effect of PBE was evaluated by measuring the nitric oxide (NO) concentration after the onset of CFA-stimulated inflammation in MH-S cells. Polymerase chain reaction (PCR) was used to examine inflammatory gene expression. Western blotting and immunofluorescence (IF) studies were used to investigate the inflammatory mechanism in MH-S cells. According to our results, the PBE suppressed CFA-induced NO generation in the MH-S cells dose-dependently. Furthermore, PBE inhibited the proinflammatory mediators and cytokines generated by exposure to CFA, including cyclooxygenase 2 (COX-2) and inducible NO synthase (iNOS), interleukin (IL)-1 $\beta$, IL-6, and tumor necrosis factor-alpha (TNF- $\alpha$ ). Real-time PCR was also used to determine the inhibiting effect of the PBE on proinflammatory factors such as COX-2, iNOS, IL- $1 \beta$, IL-6, and TNF- $\alpha$. Moreover, Western blot was used to assess the effects of the PBE on the nuclear factor-kappa B (NF- $\kappa \mathrm{B}$ ) and mitogen-activated protein kinase (MAPK) pathways in the CFA-stimulated MH-S cells. The suppressive effect of the PBE on phosphorylated (p)-NF- $\kappa \mathrm{B}$ translocation was also investigated using IF analysis. This study showed that the PBE suppressed the CFA-induced inflammation in the MH-S cells by suppressing the NF- $\kappa$ B and MAPK signaling pathways, which suggests its potential usefulness in reducing lung inflammation.
\end{abstract}

\section{Introduction}

Inflammation is an important aspect of the immune system's defense against damaging stimuli $[1,2]$. Dysregulated inflammation is linked to various chronic disorders [3, 4]. Macrophages play an important role in the operation of inflammatory processes, primarily by producing proinflammatory mediators and cytokines such as nitric oxide (NO), inducible NO synthase (iNOS), cyclooxygenase 2 (COX-2), interleukin $1 \beta$ (IL-1 $\beta$ ), IL-6, and tumor necrosis factor- $\alpha$ (TNF- $\alpha)$ [4]. Thus, the inhibition of the proinflammatory macrophage activation is considered a vital approach for treating inflammatory disorders.

Particulate matter (PM) in contaminated air is becoming a critical source of health issues [5]. Chronic PM exposure has been linked to chronic inflammatory disorders, particularly severe lung diseases such as chronic respiratory diseases, chronic obstructive pulmonary diseases, asthma, and several types of lung cancer [6-8]. Many pathological and clinical signs of airway inflammatory disorders are linked to excessive production of proinflammatory mediators and cytokines $[9,10]$. Alveolar macrophages (MH-S) are 
immune cells in the immunological regulatory system that are found in the pulmonary alveoli and responsible for upregulating inflammatory mediators caused by exposure to coal fly ash (CFA).

Phellinus baumii, a wild fungus, has traditionally been used as healthy food or a folk tonic in East Asia because of its multiple physiological functions, including blood lipid levellowering, antitumor, antiinfluenza, and antioxidation capacities, and DNA damage-protecting, immune-stimulating, and antidiabetic activities [11-13]. Polysaccharides, polyphenols, and flavonoids, which have a wide spectrum of health benefits and biological activities, have been reported as the principal bioactive ingredients of the Phellinus fungus in modern medical research [14-16]. The Phellinus fungus includes various yellow polyphenolic chemicals, such as hispidin, that have demonstrated substantial biological effects and have been used to treat diabetes, bacterial, and viral infections, ulcers, and cancer, according to prior studies $[11,17]$.

Using NO and cell viability assays, as well as the mRNA and protein expressions of proinflammatory cytokines and mediators, we evaluated the anti-inflammatory effects of the Phellinus baumii extract (PBE) on CFA-stimulated MH-S cells.

\section{Materials and Methods}

2.1. Chemicals and Reagents. RPMI medium for MH-S cells culture, $10 \%$ of fetal bovine serum (FBS), $1 \%$ of penicillin-streptomycin, Dulbecco's phosphate-buffered saline, 3-(4,5-dimethylthiazol-2-yl)-2,5-diphenyltetrazolium bromide (MTT), coal fly ash (CFA), dimethyl sulfoxide (DMSO) (Sigma-Aldrich, MO, USA); oligo-dT and iNOS, COX-2, IL$1 \beta$, IL-6, and TNF- $\alpha$ primers (Bioneer, Daejeon, Republic of Korea); TRIzol reagent (Invitrogen, CA, USA); proprep (iNtRON Biotechnology, Republic of Korea); bovine serum albumin (BSA) (Thermo Fisher Scientific, Republic of Korea); primary antibodies including phosphorylated (p)$\mathrm{I} \kappa \mathrm{B}, \mathrm{p}-\mathrm{NF}-\kappa \mathrm{B}$, and NOD-like receptor protein 3 (NLRP3), phosphorylated extracellular signal-regulated kinase ( $\mathrm{p}$ ERK), total (T)-ERK, phosphorylated c-Jun N-terminal kinase (p-JNK), T-JNK, p-p38, T-p38, $\beta$-actin, and horseradish peroxidase-linked secondary antibody were used (Cell Signaling Technology, Danvers, MA, USA). A secondary antibody was used for immunofluorescence (IF) (Alexa Fluor 555, IgG Fab2, Molecular Probes). Other reagents were obtained from Sigma-Aldrich.

2.2. Preparation of the Phellinus baumii Extract (PBE). We purchased Phellinus baumii, which we ground into a coarse powder. We next extracted in $70 \%$ ethanol for $24 \mathrm{~h}$ using an extractor at $60^{\circ} \mathrm{C}$, followed by concentration using the rotary evaporator under reduced pressure. To make a fine powder, the crude extract was frozen overnight at $-70^{\circ} \mathrm{C}$ and lyophilized using a freeze dryer. Finally, the dried extract was ground into a fine powder. During the experiment, the powder was dissolved in DMSO. The concentrate was partitioned using hexane and water, and the hexane-soluble fraction was discarded. The water-soluble fraction was extracted with ethyl acetate. The ethyl acetate-soluble fraction contained yellowish polyphenols of the styrylpyrone class and various oils. Oils were eliminated by washing with chloroform. The remaining polyphenol cluster was dried and powdered for further experiments [18].

2.3. Cell Culture and Treatment. The MH-S macrophages were cultured in the RPMI medium and supplemented with $10 \%$ heat-inactivated FBS and $1 \%$ antibiotics $(100$ unit $/ \mathrm{mL}$ penicillin and $100 \mu \mathrm{g} / \mathrm{mL}$ streptomycin), according to our previously described method [19]. The cells were then incubated at $37^{\circ} \mathrm{C}$ with $5 \% \mathrm{CO}_{2}$ in a humidified incubator.

2.4. Nitric Oxide Assay. The Griess reagents A and B were used to measure $\mathrm{NO}$ concentration in accordance with our previous study $[7,19]$. In a 24 -well plate, $\mathrm{MH}-\mathrm{S}$ cells were seeded and cultured for $18 \mathrm{~h}$ with or without CFA $(2.5 \mu \mathrm{g} /$ $\mathrm{mL})$ and $\operatorname{PBE}(12.5,25,50$, and $100 \mu \mathrm{g} / \mathrm{mL})$ at the doses indicated. $100 \mu \mathrm{L}$ of Griess reagents were mixed with $100 \mu \mathrm{L}$ of cell culture supernatants and incubated for $10 \mathrm{~min}$ at room temperature. On a microplate reader, the absorbance at $540 \mathrm{~nm}$ was measured (VersaMax, Molecular Devices, CA, USA).

2.5. Cell Viability Assay. A cell viability experiment was performed as stated using a MTT reagent at $100 \mu \mathrm{L} /$ well in the culture medium to test the cytotoxicity, as described previously $[7,19]$. The supernatants were removed after 2$3 \mathrm{~h}$ of incubation at $37^{\circ} \mathrm{C}$ in $5 \% \mathrm{CO}_{2}$. The wells were filled with DMSO $(100 \mu \mathrm{L} /$ well $)$ and incubated for $10 \mathrm{~min}$ at room temperature with shaking. Finally, the absorbance was measured at $560 \mathrm{~nm}$ using a microplate reader (VersaMax, Molecular Devices, CA, USA).

2.6. Reverse Transcription Polymerase Chain Reaction and Quantitative Real-Time Polymerase Chain Reaction. Using previously described methods, a polymerase chain reaction (PCR) analysis was done [7, 19]. PBE $(12.5,25,50$, and $100 \mu \mathrm{g} / \mathrm{mL}$ ) was applied to cells at the doses indicated for $30 \mathrm{~min}$, followed by $18 \mathrm{~h}$ of CFA stimulation $(2.5 \mu \mathrm{g} / \mathrm{mL})$. The RNA was extracted from the cells using the TRIzol reagent.

Two micrograms of total RNA were annealed with oligo$\mathrm{dT}$ at $70^{\circ} \mathrm{C}$ for $10 \mathrm{~min}$ and cooled for $10 \mathrm{~min}$ on ice before reverse transcription (RT) in $20 \mu \mathrm{L}$ of reaction mixture at $42^{\circ} \mathrm{C}$ for $90 \mathrm{~min}$ on a thermocycler. To inactivate the reverse transcriptase, the reaction was stopped at $95^{\circ} \mathrm{C}$ for $5 \mathrm{~min}$. In a PCR premix, cDNA produced from an RT reaction was used to perform a RT-PCR (Bioneer). On 1\% agarose gel stained with ethidium bromide, the PCR products were electrophoresed. ImageQuant LAS 500 was used to visualize the band (GE Healthcare Life Sciences, Republic of Korea). Glyceraldehyde-3-phosphate dehydrogenase (GAPDH) was used as a house keeping gene. SYBR green was used in the real-time PCR. The primer sequences for RT-PCR and realtime PCR are given in Table 1. 
TABle 1: Primers were used for reverse transcription polymerase chain reaction (RT-PCR) and real-time PCR analysis.

\begin{tabular}{lrc}
\hline RT-PCR & Forward primer sequences $\left(5^{\prime}-3^{\prime}\right)$ & Reverse primer sequences $\left(5^{\prime}-3^{\prime}\right)$ \\
\hline iNOS & CCCTTCCGAAGTTCTGGCAGCAGC & GGCTGTCAGAGCCTCGTGGCTTTGG \\
COX-2 & CACTACATCCTGACCCACTT & ATGCTCCTGCTTGAGTATGT \\
IL- $\beta$ & CTGTGGAGAAGCTGTGGCAG & GGGATCCACACTCTCCAGCT \\
IL-6 & GTACTCCAGAAGACCAGAGG & TGCTGGTGACAACCACGGCC \\
TNF- $\alpha$ & TTGACCTCAGCGCTGAGTTG & CCTGTAGCCCACGTCGTAGC \\
GAPDH & CACTCACGGCAAATTCAACGGCAC \\
Real-time PCR & & GACTCCACGACATACTCAGCAC \\
iNOS & GGCAGCCTGTGAGACCTTTG & \\
COX-2 & GGCAGCCTGTGAGACCTTTG & GCATTGGAAGTGAAGCGTTTC \\
IL-1 $\beta$ & CAACCAACAAGTGATATTCTCCATG & GCATTGGAAGTGAAGCGTTTC \\
IL-6 & TCCAGTTGCCTTCTTGGGAC & GATCCACACTCTCCAGCTGCA \\
GAPDH $\alpha$ & TGCCTATGTCTCAGCCTCTTC & GTGTAATTAAGCCTCCGACTTG \\
\hline
\end{tabular}

2.7. Western Blot Analysis. Western blotting was performed with several changes, as described previously [4, 19]. Proteins were isolated from cells, concentrations were determined, and samples were prepared in sodium dodecyl sulfate (SDS) and heated for $5 \mathrm{~min}$. SDS-polyacrylamide gel electrophoresis (SDS-PAGE) was used to separate the samples. The proteins were deposited to the poly (vinylidene fluoride) membranes and blocked for $1 \mathrm{~h}$ at room temperature with skim milk (5\%). The membranes were washed with washing buffer, tris-buffered saline with Tween (TBST) three times for $10 \mathrm{~min}$ each time, and treated overnight at $4^{\circ} \mathrm{C}$ with the primary antibodies $(1$ : 1000), namely, p-I $\kappa \mathrm{B}, \mathrm{p}-\mathrm{NF}-\kappa \mathrm{B}, \mathrm{NLRP} 3, \mathrm{p}-\mathrm{JNK}, \mathrm{T}-\mathrm{JNK}$, p-ERK, T-ERK, p-p38, T-p38, and $\beta$-actin. Furthermore, the membranes were washed with TBST three times for 10 min each time and then incubated with horseradish peroxidase-labeled secondary antibodies $(1: 3000)$ for $1 \mathrm{~h}$ before rinsing with TBST three times for $10 \mathrm{~min}$ each. Enhanced chemiluminescence (ECL) solutions A and B (1 : 1 ratio) were used to detect the protein bands in Imager LAS 500 (General Electrics, Boston, MA, USA).

2.8. Immunofluorescence Analysis. The immunofluorescence (IF) experiment was performed as described previously $[4,19]$. The MH-S cells were rinsed with DPBS and fixed for $10 \mathrm{~min}$ in $4 \%$ paraformaldehyde. The cells were also permeabilized for 10 min with $0.2 \%$ triton $\mathrm{X}-100$ in TBS (TBST) and rinsed three times with TBST for $5 \mathrm{~min}$ each time. The samples were blocked for $1 \mathrm{~h}$ with $2 \%$ BSA before adding rabbit anti-p-NF- $\kappa \mathrm{B}$ (primary antibody) overnight at $4^{\circ} \mathrm{C}$. $\mathrm{MH}-\mathrm{S}$ cells were rinsed three times with TBST for $5 \mathrm{~min}$ each time. The samples were incubated for $1 \mathrm{~h}$ in the dark with a secondary antibody and then washed three times with TBST before being mounted with a Prolong Gold Antifade reagent with 4,6-diamidino-2-phenylindole (DAPI) (Cell Signaling Technology) to observe the nuclei and examined using confocal microscopy (LSM700, Carl Zeiss, Jena, Germany).

2.9. Statistical Analysis. The data are represented using the mean and standard error of the mean. One-way analysis of variance was used to establish the statistical significance. The statistical analysis results were considered significant at ${ }^{*} p$ values $<0.05,{ }^{* *}<0.01$, and ${ }^{* * *}<0.001$ in comparison to the CFA only group and at ${ }^{\#} p$ values $<0.001$ in comparison to the basal group.

\section{Results}

3.1. Phellinus baumii Extract Protected against Coal Fly AshInduced Nitric Oxide (NO) Generation and Cell Death in the Alveolar Macrophage Cells. NO is a key mediator in the inflammatory process, and its overproduction contributes to the development of inflammatory disorders. The Griess reaction method was used to quantify the NO levels in the murine $\mathrm{MH}-\mathrm{S}$ in response to $\mathrm{CFA}$ stimulation in this investigation. The NO induction was potently reduced by $\mathrm{PBE}$ dose-dependently (Figure 1(a)).

Cell vitality was determined using the MTT test, and the results showed that the PBE had no effect on cell toxicity compared with the basal group at the different concentrations used (Figure 1(b)). These findings showed that PBE suppressed the NO generation dose-dependently and that the dosages used were not cytotoxic.

3.2. Suppressive Effect of Phellinus baumii Extract on Coal Fly Ash-Induced Proinflammatory Cytokines in the Alveolar Macrophage Cells. The levels of the CFA-induced proinflammatory factors were reduced in $\mathrm{MH}-\mathrm{S}$ after $30 \mathrm{~min}$ of pretreatment with $\mathrm{PBE}$. To investigate the anti-inflammatory properties of the PBE, the mRNA expression of iNOS and COX-2, IL- $1 \beta$, IL- 6 , and TNF- $\alpha$ were examined using RT-PCR. Levels of the proinflammatory factors were shown to be reduced dose-dependently (Figures 2(a)-2(f)). This result revealed that the $\mathrm{PBE}$ inhibited CFA-induced production of inflammatory cytokines and lowered the mRNA levels significantly.

3.3. Phellinus baumii Extract Ameliorated the Coal Fly AshInduced mRNA Expressions of Proinflammatory Cytokines in the Alveolar Macrophage Cells. To validate the RT-PCR results for proinflammatory factors in the $\mathrm{MH}-\mathrm{S}$ cells, the mRNA expressions of proinflammatory mediators and 


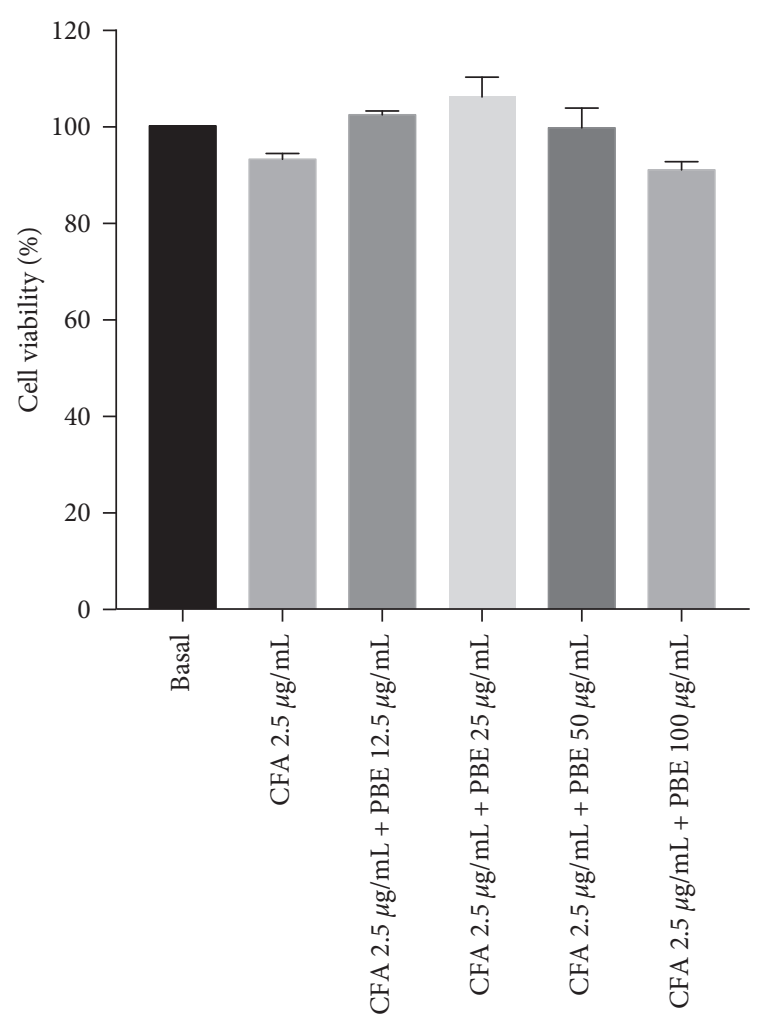

(a)

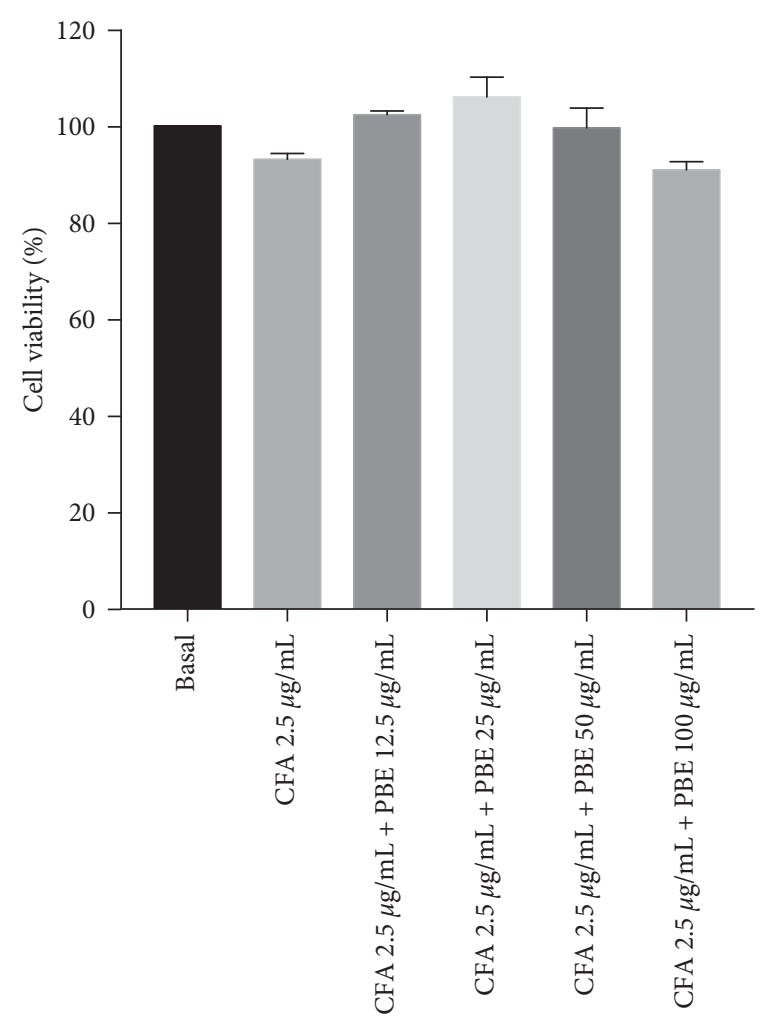

(b)

Figure 1: Effect of Phellinus baumii extract (PBE) on coal fly ash (CFA)-stimulated nitric oxide (NO) generation and cell viability in MH-S macrophages. (a) The cells are divided into six groups, namely, the control (basal), CFA only $(2.5 \mu \mathrm{g} / \mathrm{mL})$, and CFA with PBE (12.5, 25, 50, and $100 \mu \mathrm{g} / \mathrm{mL}$ ) groups. The cells are treated with the abovementioned PBE concentrations for 30 min prior to the CFA treatment and incubated for $18 \mathrm{~h}$. The NO level is determined using the Griess reagent method. (b) The MTT reagent method used to perform the cell viability experiment. A 24 -well plate is used to seed the cells. All the values from the three independent experiments are expressed as standard error of the mean. ${ }^{\#} P<0.001$ in comparison to the basal group. ${ }^{*} P<0.05,{ }^{* *} P<0.01$, and ${ }^{* * *} P<0.001$ in comparison to the CFA group.

cytokines were investigated, and those of proinflammatory factors were tested by real-time PCR. The PBE administration significantly reduced the mRNA expression levels of proinflammatory mediators and cytokines in a dose-dependent manner (Figures 3(a)-3(e)). The real-time PCR results demonstrated that $\mathrm{PBE}$ lowered proinflammatory factors in a concentration-dependent manner.

\subsection{Phellinus baumii Extract Inhibits the Activation of the} Nuclear Factor- $\kappa B$ (NF- $\kappa B$ ) and Mitogen-Activated Protein Kinase (MAPK) Signaling Pathways in the Coal Fly AshTreated Alveolar Macrophage Cells. It was hypothesized that the effect of PBE on NF- $\kappa \mathrm{B}$ and MAPK signaling played a crucial role in inflammation. CFA activates the inflammatory pathway, and NF- $\kappa \mathrm{B}$ and MAPK are critical pathways in the inflammatory cascade. Treatment with PBE considerably decreased the NF- $\kappa$ B phosphorylation and the inhibitor of kappa B ( $\mathrm{\kappa} \kappa$ B) phosphorylation, whereas CFA markedly enhanced phosphorylation of NF- $\kappa \mathrm{B}$, a transcription factor and inhibitor of kappa B (I $\kappa$ B) in MH-S cells.

NLRP3 was also dose-dependently downregulated after treatment with $\mathrm{PBE}$, especially at $100 \mu \mathrm{g} / \mathrm{mL}$. In addition, the
MAPK pathways, including p-JNK, p-p38, and p-ERK, were also significantly dose-dependently inhibited after treatment with $\mathrm{PBE}$ compared with treatment with CFA alone. These results suggest that the pretreatment with $\mathrm{PBE}$ significantly inhibited the CFA-induced NF- $\kappa \mathrm{B}, \mathrm{I} \kappa \mathrm{B}, \mathrm{NLRP} 3, \mathrm{ERK}$, JNK, and p38 activation in MH-S cells (Figures 4(a)-4(g)).

\subsection{Phellinus baumii Extract Inhibited the Translocation of} $N F-\kappa B$ in the Coal Fly Ash-Treated Alveolar Macrophage Cells. In CFA-stimulated macrophages, activated p-NF- $\kappa \mathrm{B}$ translocation from the cytoplasm to the nucleus was examined using an IF assay to see if PBE's anti-inflammatory effects are mediated through signal transduction cascade of NF- $\kappa \mathrm{B}$. CFA treatment promoted the NF- $\kappa \mathrm{B}$ translocation from the cytoplasm to the nucleus, but treatment with the maximum dose of PBE $(100 \mu \mathrm{g} / \mathrm{mL})$ dramatically inhibited $\mathrm{p}-\mathrm{NF}-\kappa \mathrm{B}$ nuclear translocation in activated macrophages (Figure 5). Bay-11 was used as an NF- $\kappa$ B inhibitor. According to the immunostaining result, the anti-inflammatory activities of PBE were linked to its inhibiting properties of the NF- $\kappa \mathrm{B}$ phosphorylation signaling cascade. 


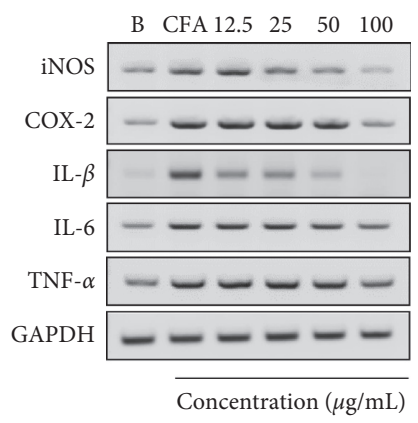

(a)

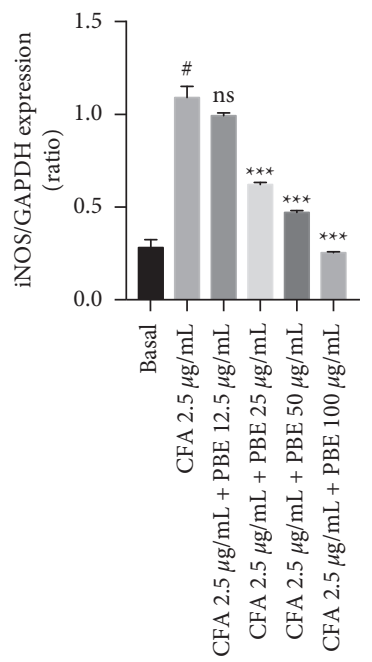

(b)

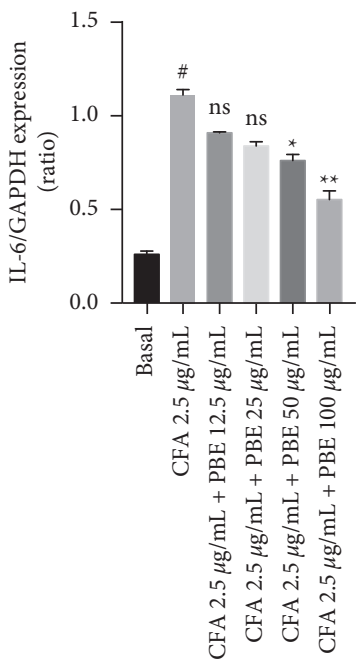

(e)

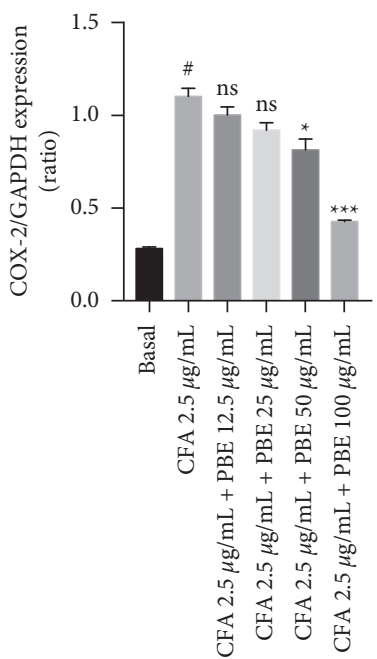

(c)

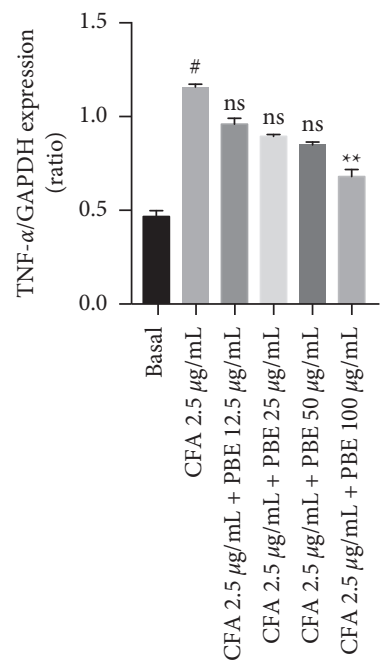

(f)

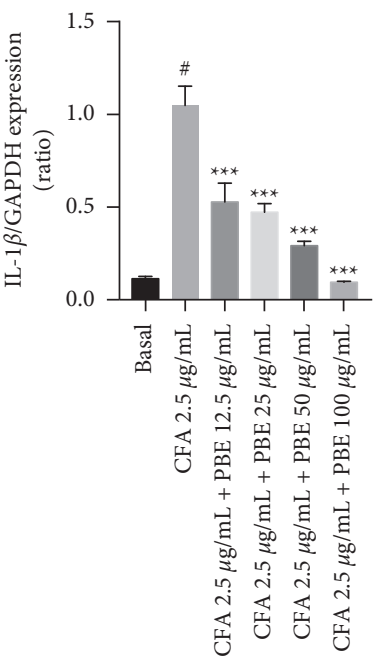

(d)

FIGURE 2: Effect of PBE on CFA-stimulated proinflammatory mediators and cytokines in MH-S macrophages analyzed using reverse transcription polymerase chain reaction (RT-PCR). (a) The mRNA levels of proinflammatory mediators (iNOS and COX-2) and proinflammatory cytokines (IL- $1 \beta$, IL- 6 , and TNF- $\alpha$ ) measured after $18 \mathrm{~h}$ of CFA $(2.5 \mu \mathrm{g} / \mathrm{mL}$ ) incubation and GAPDH utilized as a housekeeping gene in RT-PCR. (b-f) The levels of protein expression densitometrically analyzed using ImageJ software. A 6-well plate is used to seed the cells, and the PBE doses of $12.5,25,50$, and $100 \mu \mathrm{g} / \mathrm{mL}$ are used. All the values from three independent experiments are expressed as standard error of the mean. ${ }^{\#} P<0.001$ in comparison to the basal group. ${ }^{*} P<0.05,{ }^{* *} P<0.01$, and ${ }^{* * *} P<0.001$ in comparison to the CFA group.

\section{Discussion}

As medicinal herbs have been widely studied for its anti-inflammatory properties [20,21], we desire to investigate effective medicinal herbs that have potent medicinal properties. Phellinus baumii has long been used as herbal medicine in Asia, particularly China, Korea, and Japan for the treatment of a variety of ailments, including diabetes, hypercholesterolemia, and most notably cancer $[11,22]$. Earlier studies showed that PBE can block NF- $\kappa \mathrm{B}$, transcription factor, which is a crucial regulator in the inflammatory cascade. The effects of Phellinus baumii on CFA-activated inflammation in the alveolar macrophage cell line were investigated in this work.

The extremely high production of NO related to iNOS synthesis is involved in the inflammatory process $[23,24]$. iNOS plays a vital role in releasing $\mathrm{NO}$ during the pathophysiology of inflammatory diseases $[25,26]$. Moreover, COX-2 is also stimulated by inflammatory stimuli during the inflammatory response $[27,28]$. In our study, only the CFAstimulated group showed upregulation of $\mathrm{NO}$ production compared with the basal group, whereas pretreatment with $\mathrm{PBE}$ reduced the NO production. The combined treatment 


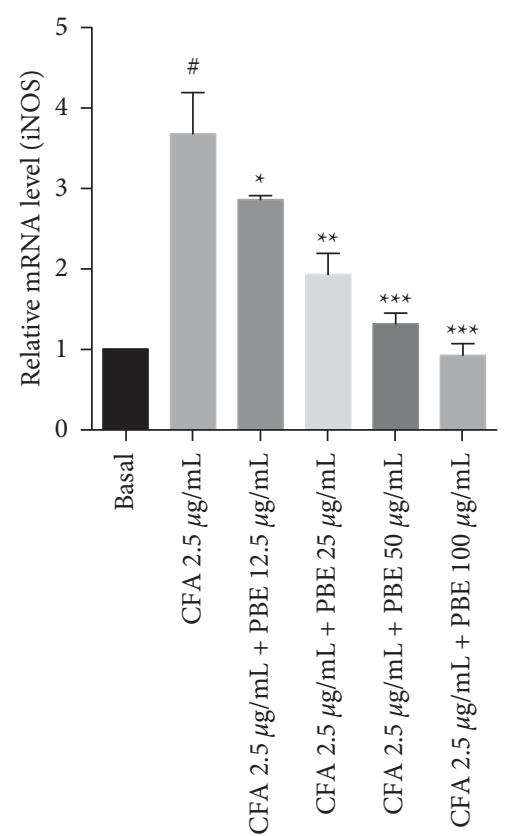

(a)

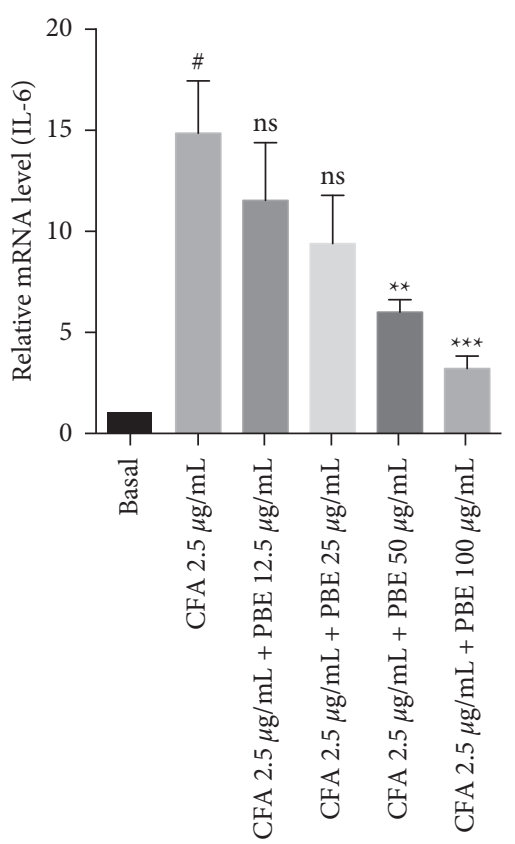

(d)

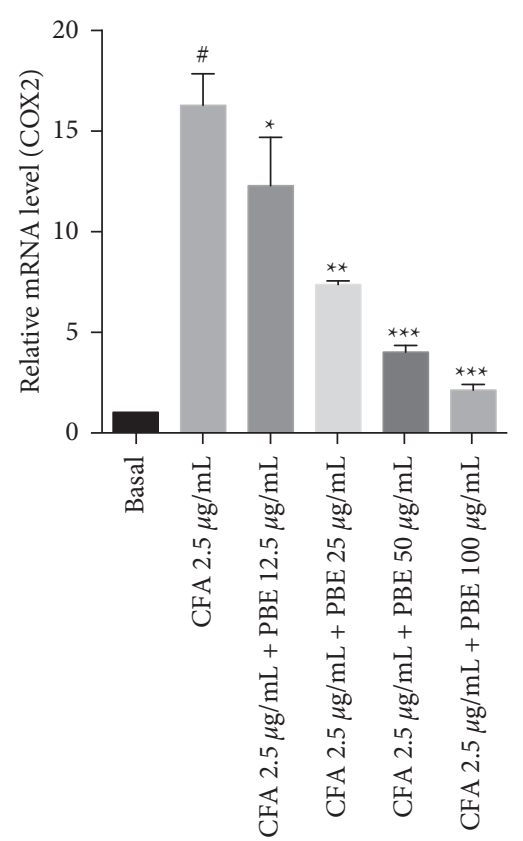

(b)

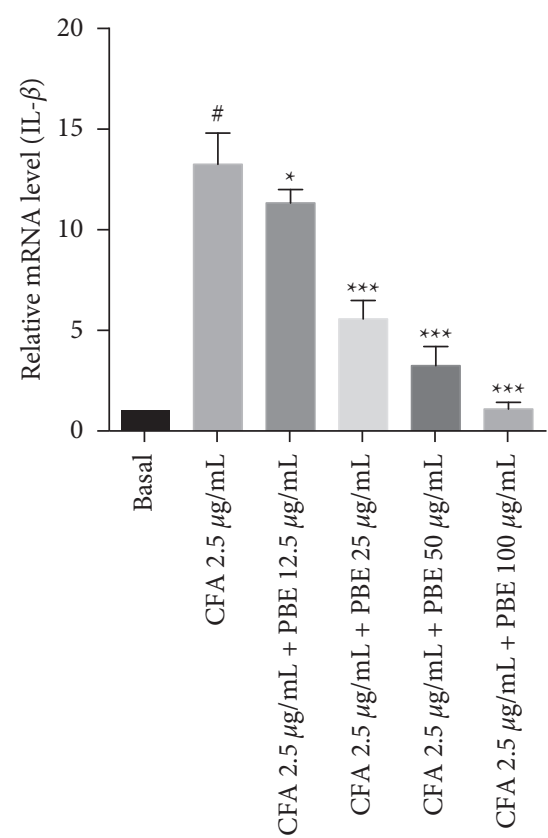

(c)

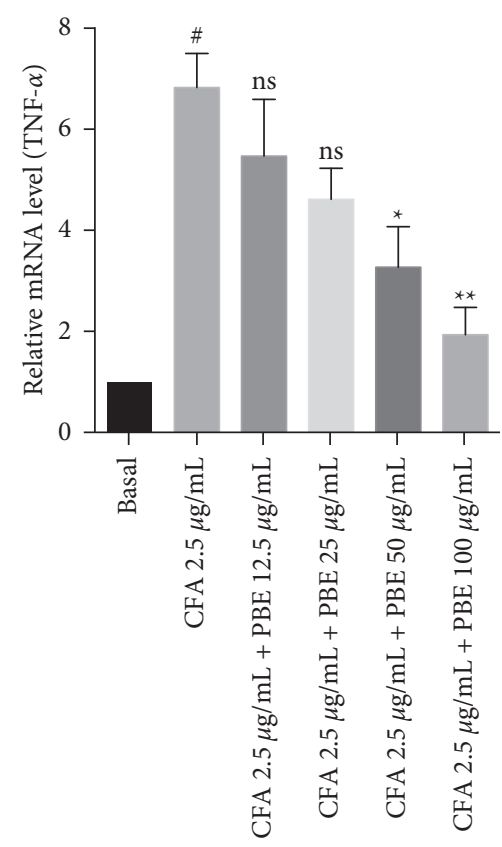

(e)

FIGURE 3: Effect of PBE on CFA-stimulated mRNA expression in MH-S macrophages measured using real-time polymerase chain reaction (PCR). (a-e) The mRNA levels of iNOS, COX-2, IL-1 $\beta$, IL-6, and TNF- $\alpha$ are measured by quantitative real-time PCR after $18 \mathrm{~h}$ of CFA $(2.5 \mu \mathrm{g} / \mathrm{mL})$ incubation. GAPDH is used as a control gene. A 6-well plate is used to seed the cells, and PBE doses of 12.5, 25, 50, and $100 \mu \mathrm{g} / \mathrm{mL}$ are used. All the values from three independent experiments are expressed as standard error of mean. ${ }^{\#} P<0.001$ in comparison to the basal group. ${ }^{*} P<0.05,{ }^{* *} P<0.01$, and ${ }^{* * *} P<0.001$ in comparison to the CFA group.

with PBE significantly decreased the NO induction (Figure 1(a)).

Endotoxins and cytokines prompted fast alterations in the NO gene expression throughout the inflammation process, which resulted in the de novo synthesis of iNOS and COX-2 pathways $[24,29]$. The mRNA expression levels of the proinflammatory mediators such as iNOS and COX-2 and the proinflammatory factors such as IL- $1 \beta$, IL-6, and TNF- $\alpha$ were upregulated in the CFA-treated group. By contrast, the combination treatment with $\mathrm{PBE}$ significantly downregulated the mRNA levels of the proinflammatory factors (Figures 2(a)-2(f)). These results suggest that PBE 


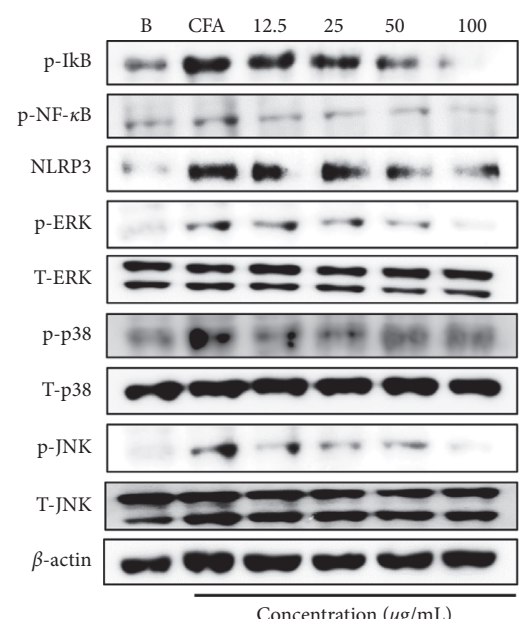

Concentration $(\mu \mathrm{g} / \mathrm{mL})$

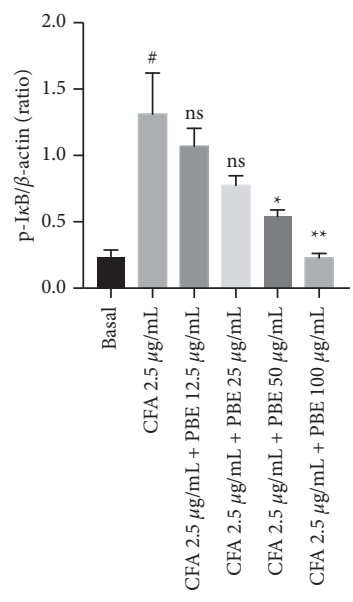

(b)

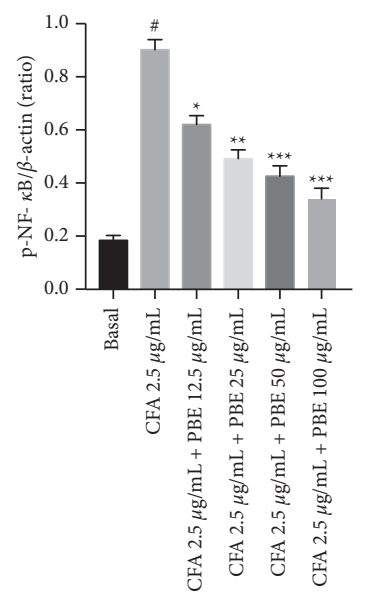

(c)

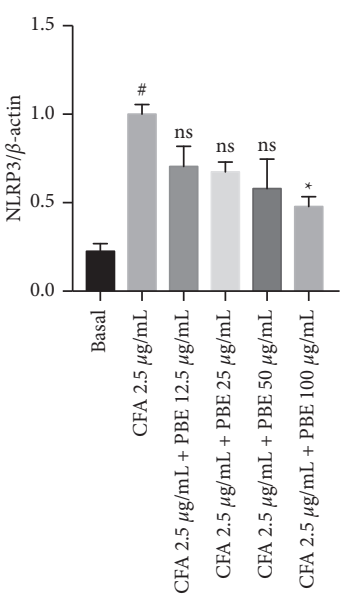

(d)

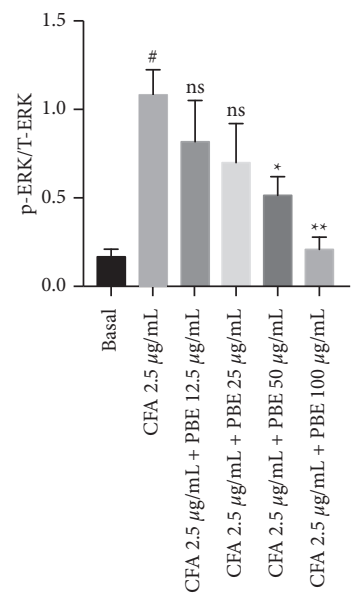

(e)

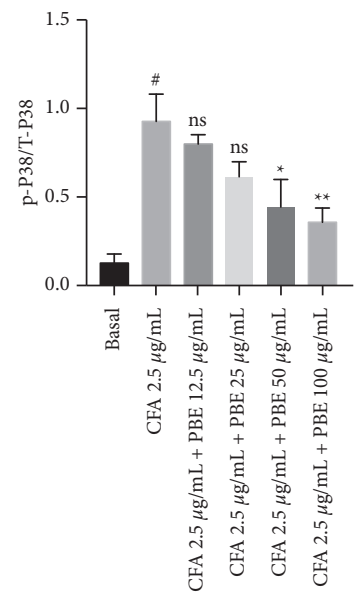

(f)

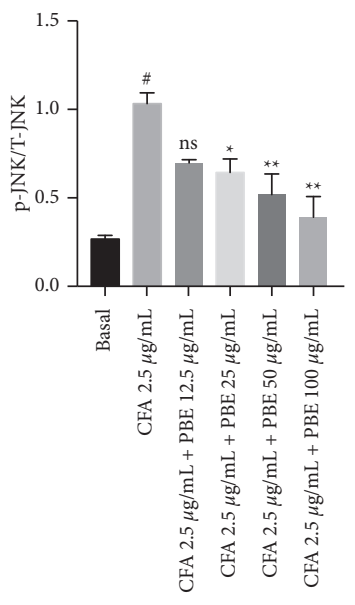

(g)

FIGURE 4: Effect of PBE on CFA-stimulated nuclear factor-kappa B (NF- $\kappa$ B) and mitogen-activated protein kinase (MAPK) pathways in MH-S macrophages. (a) The protein levels of $\mathrm{p}-\mathrm{I} \kappa \mathrm{B}$, phosphorylated NF- $\kappa \mathrm{B}$, and NOD-like receptor protein 3 , and the MAPK (extracellular signal-regulated kinase, p38, and c-Jun N-terminal kinase) pathway investigated using Western blot after $18 \mathrm{~h}$ of $\mathrm{CFA}(2.5 \mu \mathrm{g} / \mathrm{mL})$ incubation. As a loading control, $\beta$-actin was used. (b-g) The expression levels of protein were densitometrically analyzed using ImageJ software. A 6-well plate is used to seed the cells, and the PBE doses of $12.5,25,50$, and $100 \mu \mathrm{g} / \mathrm{mL}$ are used. All the values from three independent experiments are expressed as standard error of the mean. ${ }^{\#} P<0.001$ in comparison to the basal group. ${ }^{*} P<0.05,{ }^{* *} P<0.01$, and ${ }^{* * *} P<0.001$ in comparison to the CFA group.

has the potential to inhibit proinflammatory factors. Our results also support the previous findings that the iNOS and COX-2 expressions were upregulated in the CFA-stimulated group [19] and that treatment with PBE significantly reduced the protein levels of iNOS and COX-2 (Figures 3(a)$3(\mathrm{e}))$.

The NF- $\kappa$ B and MAPK signaling pathways were reported to be the key pathways for the inflammatory process [30-32]. The transcription factor $\mathrm{NF}-\kappa \mathrm{B}$ is a critical regulator in the inflammatory cascade [19]. The MAPK signaling pathway plays an important role in the inflammatory mechanism [33]. Therefore, we examined the anti-inflammatory mechanism of PBE in the macrophage cell line. The protein expression levels of $\mathrm{p}-\mathrm{I} \kappa \mathrm{B}, \mathrm{p}-\mathrm{NF}-\kappa \mathrm{B}, \mathrm{NLRP} 3$, $\mathrm{p}-\mathrm{ERK}, \mathrm{T}-\mathrm{ERK}$, p-p38, T-p38, p-JNK, and T-JNK were investigated using Western blotting. For the macrophage $\mathrm{MH}-\mathrm{S}$ cell line treated with CFA, the activity levels of the NF- $\kappa \mathrm{B}$ and MAPK signaling pathways were increased by the CFA treatment, 


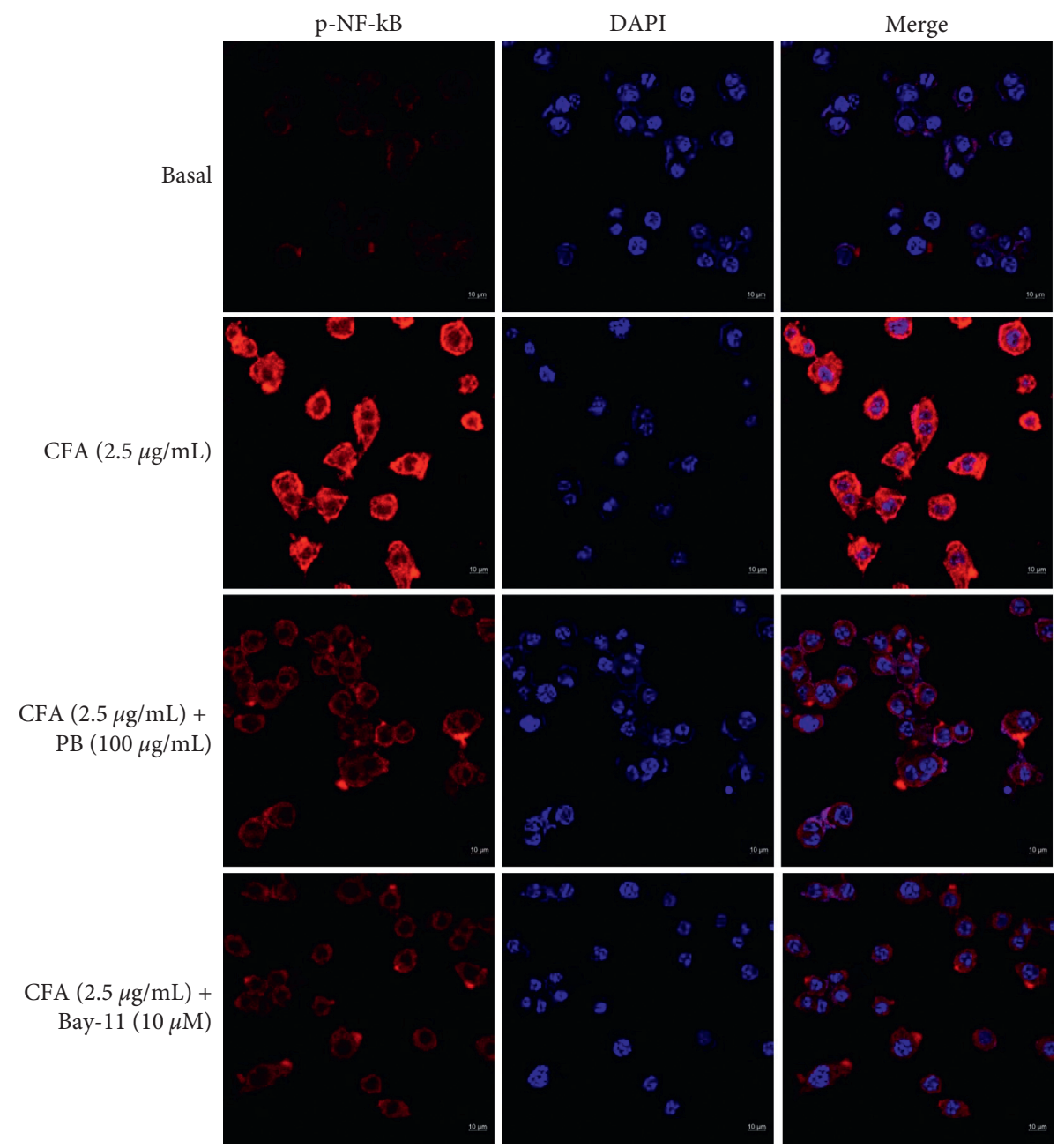

Figure 5: Effect of PBE on CFA-stimulated nuclear factor-kappa B (NF- $\kappa$ B) translocation in MH-S macrophages. The cells are seeded on a coated cover slip in a 6-well plate and grouped as follows: basal, CFA $(2.5 \mu \mathrm{g} / \mathrm{mL})$-induced, CFA with PBE $(100 \mu \mathrm{g} / \mathrm{mL})$, and CFA with Bay11 , inhibitor of phosphorylated (p-NF- $\kappa \mathrm{B}$ ) groups. The cells are treated with PBE and Bay-11 $(10 \mu \mathrm{M})$ for 30 min prior to the CFA treatment $(2.5 \mu \mathrm{g} / \mathrm{mL})$ and incubated for $18 \mathrm{~h}$. Immunofluorescence staining is used to examine p-NF- $\kappa \mathrm{B}$ nuclear translocation. To visualize the nuclei, the samples are mounted using a Prolong Gold Antifade reagent with DAPI (blue). Confocal microscopy (Zeiss) at $\times 400$ original magnification is used to examine stained cells.

whereas treatment with PBE significantly suppressed the NF- $\kappa \mathrm{B}$ and MAPK signaling protein expressions (Figures $4(\mathrm{a})-4(\mathrm{~g}))$. On the basis of our findings, we hypothesized that PBE would decrease $\mathrm{I} \kappa \mathrm{B}$ and NF- $\kappa \mathrm{B}$ phosphorylation, causing the proinflammatory factors to be suppressed.

Furthermore, IF staining revealed that CFA increased the $\mathrm{p}-\mathrm{NF}-\kappa \mathrm{B}$ translocation in the nucleus, whereas $\mathrm{PBE}$ $(100 \mu \mathrm{g} / \mathrm{mL})$ and Bay-11 $(10 \mu \mathrm{M})$ significantly decreased the $\mathrm{p}-\mathrm{NF}-\kappa \mathrm{B}$ translocation from the cytoplasm to the nucleus
(Figure 5). A similar result was also found in our previous study $[19,34]$. Bay-11 has been reported to have an antiinflammatory activity that inhibits the phosphorylation of $\mathrm{I} \kappa \mathrm{B}$ [35]. Our findings suggest that PBE inhibited CFAstimulated inflammation by reducing the activity levels of NF- $\kappa$ B and MAPK signaling pathways (Figure 6). Only in vitro experiments were performed in this study. Large-scale animal excrement should be performed to reveal the specific mechanism of the action of PBE as an anti-inflammatory agent. 


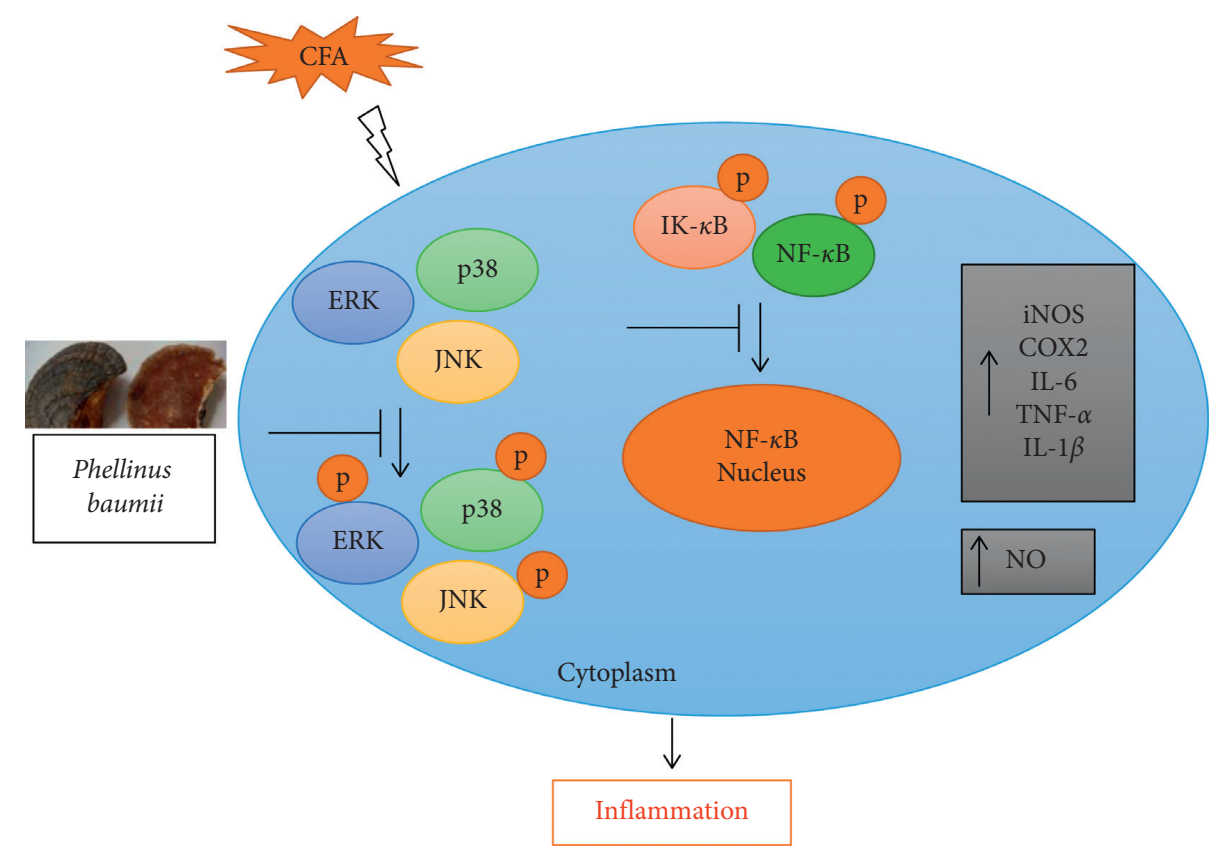

FIgURE 6: Mechanism of action of PBE in CFA-stimulated inflammation in MH-S macrophages.

\section{Conclusion}

In conclusion, the anti-inflammatory effects of PBE were established in the CFA-stimulated alveolar macrophages. The findings of this work add to our understanding of CFAinduced inflammatory responses and reveal that PBE may decrease proinflammatory factors expression in $\mathrm{MH}-\mathrm{S}$ cells. According to our findings, the PBE has potential anti-inflammatory qualities for the regulation of inflammation and could be used as an herbal remedy in the prevention and treatment of numerous inflammatory disorders.

\section{Data Availability}

The data used to support the findings of this study are included within the article.

\section{Conflicts of Interest}

The authors declare that they have no conflicts of interest.

\section{Acknowledgments}

This study was funded and supported by the National Research Foundation (NRF) of Korea (2018R1D1A1A09083797).

\section{References}

[1] H. M. A. Ullah, S. Zaman, F. Juhara et al., "Evaluation of antinociceptive, in-vivo \& in-vitro anti-inflammatory activity of ethanolic extract of Curcuma zedoaria rhizome," BMC Complementary and Alternative Medicine, vol. 14, no. 1, p. 346, 2014.

[2] H.-N. Lee, H.-K. Na, and Y.-J. Surh, "Resolution of inflammation as a novel chemopreventive strategy," Seminars in Immunopathology, vol. 35, no. 2, pp. 151-161, 2013.
[3] E. Saba, M. Irfan, D. Jeong et al., "Mediation of antiinflammatory effects of Rg3-enriched red ginseng extract from Korean Red Ginseng via retinoid X receptor $\alpha$-peroxisomeproliferating receptor $\gamma$ nuclear receptors," Journal of Ginseng Research, vol. 43, no. 3, pp. 442-451, 2019.

[4] H. M. A. Ullah, A. K. Elfadl, S. Park et al., "Nogo-A is critical for pro-inflammatory gene regulation in myocytes and macrophages," Cells, vol. 10, no. 2, 2021.

[5] S.-B. Kim, Y.-S. Seo, H. S. Kim et al., "Anti-asthmatic effects of lepidii seu Descurainiae Semen plant species in ovalbumininduced asthmatic mice," Journal of Ethnopharmacology, vol. 244, Article ID 112083, 2019.

[6] E. Saba, Y.-S. Lee, W.-K. Yang et al., "Effects of a herbal formulation, $\mathrm{KGC} 3 \mathrm{P}$, and its individual component, nepetin, on coal fly dust-induced airway inflammation," Scientific Reports, vol. 10, no. 1, Article ID 14036, 2020.

[7] Y. Y. Lee, W. K. Yang, J. E. Han et al., "Hypericum ascyron L. extract reduces particulate matter-induced airway inflammation in mice," Phytotherapy Research, vol. 35, no. 3, pp. 1621-1633, 2021.

[8] Y. F. Xing, Y. H. Xu, M. H. Shi, and Y. X. Lian, "The impact of PM2.5 on the human respiratory system," Journal of Thoracic Disease, vol. 8, no. 1, pp. E69-E74, 2016.

[9] K. Van Reeth, "Cytokines in the pathogenesis of influenza," Veterinary Microbiology, vol. 74, no. 1-2, pp. 109-116, 2000.

[10] N. Eftekhar, A. Moghimi, N. Mohammadian Roshan, S. Saadat, and M. H. Boskabady, "Immunomodulatory and anti-inflammatory effects of hydro-ethanolic extract of Ocimum basilicum leaves and its effect on lung pathological changes in an ovalbumin-induced rat model of asthma," BMC Complementary and Alternative Medicine, vol. 19, no. 1, p. 349, 2019.

[11] K. Yang, S. Zhang, Y. Geng et al., "Anti-inflammatory properties in vitro and hypoglycaemic effects of phenolics from cultivated fruit body of Phellinus baumii in type 2 diabetic mice," Molecules, vol. 26, no. 8, 2021.

[12] J.-H. Yoo, Y.-S. Lee, S. Ku, and H.-J. Lee, "Phellinus baumii enhances the immune response in cyclophosphamide- 
induced immunosuppressed mice," Nutrition Research, vol. 75, pp. 15-31, 2020.

[13] T. Yayeh, W. J. Oh, S.-C. Park et al., "Phellinus baumii ethyl acetate extract inhibits lipopolysaccharide-induced iNOS, COX-2, and proinflammatory cytokine expression in RAW264.7 cells," Journal of Natural Medicines, vol. 66, no. 1, pp. 49-54, 2012.

[14] M.-M. Liu, P. Zeng, X.-T. Li, and L.-G. Shi, “Antitumor and immunomodulation activities of polysaccharide from Phellinus baumii," International Journal of Biological Macromolecules, vol. 91, pp. 1199-1205, 2016.

[15] B. S. Hwang, I.-K. Lee, H. J. Choi, and B.-S. Yun, "Anti-influenza activities of polyphenols from the medicinal mushroom Phellinus baumii," Bioorganic \& Medicinal Chemistry Letters, vol. 25, no. 16, pp. 3256-3260, 2015.

[16] S. Lee, D. Lee, T. S. Jang et al., "Anti-inflammatory phenolic metabolites from the edible fungus Phellinus baumii in LPSstimulated RAW264.7 cells," Molecules, vol. 22, no. 10, 2017.

[17] I.-K. Lee and B.-S. Yun, "Styrylpyrone-class compounds from medicinal fungi Phellinus and Inonotus spp., and their medicinal importance," Journal of Antibiotics, vol. 64, no. 5, pp. 349-359, 2011.

[18] J.-R. Noh, I.-K. Lee, Y.-H. Kim et al., "Antiatherogenic effect of antioxidant polyphenols from Phellinus baumii in apolipoprotein E-deficient mice," Annals of Nutrition and Metabolism, vol. 59, no. 2-4, pp. 145-153, 2011.

[19] H. M. A. Ullah, Y. Y. Lee, S. D. Kim, and M. H. Rhee, "Duchesnea indica extract attenuates coal fly ash-induced inflammation in murine alveolar macrophages through the NF-kappa B pathway," Evidence-based Complementary and Alternative Medicine, vol. 2021, Article ID 5546052, 2021.

[20] X. Xu, L. Jin, T. Jiang et al., "Ginsenoside Rh2 attenuates microglial activation against toxoplasmic encephalitis via TLR4/NF- $\kappa$ B signaling pathway," Journal of Ginseng Research, vol. 44, no. 5, pp. 704-716, 2020.

[21] M. Yun and Y.-S. Yi, "Regulatory roles of ginseng on inflammatory caspases, executioners of inflammasome activation," Journal of Ginseng Research, vol. 44, no. 3, pp. 373-385, 2020.

[22] K. Yang, S. Zhang, Y. Ying et al., "Cultivated fruit body of Phellinus baumii: a potentially sustainable antidiabetic resource," ACS Omega, vol. 5, no. 15, pp. 8596-8604, 2020.

[23] K. A. Kirkebøen and O. A. Strand, "The role of nitric oxide in sepsis-an overview," Acta Anaesthesiologica Scandinavica, vol. 43, no. 3, pp. 275-288, 1999.

[24] S. Saadat, F. Beheshti, V. R. Askari, M. Hosseini, N. Mohamadian Roshan, and M. H. Boskabady, "Aminoguanidine affects systemic and lung inflammation induced by lipopolysaccharide in rats," Respiratory Research, vol. 20, no. 1, p. 96, 2019.

[25] S. C. Cherng, S. N. Cheng, A. Tarn, and T. C. Chou, "Antiinflammatory activity of c-phycocyanin in lipopolysaccharide-stimulated RAW 264.7 macrophages," Life Sciences, vol. 81, no. 19, pp. 1431-1435, 2007.

[26] F. Aktan, "iNOS-mediated nitric oxide production and its regulation," Life Sciences, vol. 75, no. 6, pp. 639-653, 2004.

[27] K. Seibert and J. L. Masferrer, "Role of inducible cyclooxygenase (COX-2) in inflammation," Receptor, vol. 4, no. 1, pp. 17-23, 1994.

[28] R. Rajakariar, M. M. Yaqoob, and D. W. Gilroy, "COX-2 in inflammation and resolution," Molecular Interventions, vol. 6, no. 4, pp. 199-207, 2006.
[29] J. W. Coleman, "Nitric oxide in immunity and inflammation," International Immunopharmacology, vol. 1, no. 8, pp. 13971406, 2001.

[30] K. Xiao, C. Liu, Z. Tu et al., "Activation of the NF- $\kappa$ B and MAPK signaling pathways contributes to the inflammatory responses, but not cell injury, in IPEC-1 Cells Challenged with Hydrogen Peroxide," Oxidative Medicine and Cellular Longevity, vol. 2020, Article ID 5803639, 14 pages, 2020.

[31] T. Liu, L. Zhang, D. Joo, and S.-C. Sun, "NF- $\kappa$ B signaling in inflammation," Signal Transduction and Targeted Therapy, vol. 2, no. 1, Article ID 17023, 2017.

[32] P. Huang, J. Han, and L. Hui, "MAPK signaling in inflammation-associated cancer development," Protein \& Cell, vol. 1, no. 3, pp. 218-226, 2010.

[33] E. K. Kim and E.-J. Choi, "Pathological roles of MAPK signaling pathways in human diseases," Biochimica et Biophysica Acta-Molecular Basis of Disease, vol. 1802, no. 4, pp. 396-405, 2010.

[34] H. M. A. Ullah, T.-H. Kwon, S. Park, S. D. Kim, and M. H. Rhee, "Isoleucilactucin ameliorates coal fly ash-induced inflammation through the NF- $\kappa \mathrm{B}$ and MAPK pathways in MH-S cells," International Journal of Molecular Sciences, vol. 22, no. 17, p. 9506, 2021.

[35] S. Strickson, D. G. Campbell, C. H. Emmerich et al., "The antiinflammatory drug BAY 11-7082 suppresses the MyD88dependent signalling network by targeting the ubiquitin system," Biochemical Journal, vol. 451, no. 3, pp. 427-437, 2013. 